\title{
COVID-19: Challenges to stop an epidemic in a country with major social inequalities
}

\author{
Paola Amaral de Campos, Raquel Cristina Cavalcanti Dantas, \\ Melina Lorraine Ferreira, Rosineide Marques Ribas \\ Laboratory of Molecular Microbiology, Federal University of Uberlandia, Brazil
}

DOI: 10.3396/ijic.v16i3.023.20

A novel severe acute respiratory syndrome due to coronavirus (SARS-CoV-2), known as COVID-19, lit a warning signal about the potentially devastating effects of the pandemic, mainly on the regions with high income inequality. In Brazil, due to the abysmal levels of income inequality and limited access to health services, ${ }^{1,2}$ there are reasons to expect a calamity in the country.

In the last decade, national studies have shown a reduction in the number of deaths from infectious diseases, but this is still a public health problem in Brazil. ${ }^{3,4}$ Income generation and distribution policies for the neediest populations, the public health service (in Portuguese, Sistema Único de Saúde - SUS) and other social and environmental improvements, including basic sanitation and quality education are crucial for efforts to control infectious diseases.
As the pandemic spreads, the SUS finds it difficult to deal with the crisis. In addition to the lack of basic resources such as personal protective equipment, a shortage of intensive care beds for the sickest patients is already worrying. The pandemic threatens to collapse the Brazilian public health system and poor populations that do not have access to health services under normal circumstances are disproportionately more vulnerable in times of crisis. Furthermore, misinformation greatly affects individuals with limited access to information channels, which are more likely to ignore government health warnings.

Two seemingly simple actions represent the world we live in today - hand hygiene and social distancing. The adoption of these measures may be more difficult for countries where millions of people lack the water necessary for the first action and the physical space for

Corresponding author:

Rosineide Marques Ribas

Av. Pará, 1720, 38400-902

Uberlândia, MG, Brazil

Contact: +553432258574

E-mail: rosi_ribas@yahoo.com.br 
the second. In addition, this vulnerable people group is more susceptible to experience unemployment or financial insecurity due to labour market fluctuations resulting from macroeconomic changes.

The COVID-19 lessons tell us yet again to invest in prevention and health promotion. Besides, income preservation policies that allow the social distancing imposed by the government of Brazil are crucial to mitigate the adverse effects of the pandemic. Here, the project for a $\mathrm{R} \$ 600$ (about 100 US dollars) subsidy for informal workers in the country was sanctioned, and mothers who are solely responsible for supporting their families will be able to receive up to $R \$ 1200$.

Another concern in developing countries is the lack of an alternative to public transport used by almost all low-income people. In Brazil, despite the recommendation of the health agencies to avoid agglomerations, including in public transport, it is a mistake to suspend these services without offering alternatives that preserve access to their jobs, health posts and hospitals. The lack of investment in urban mobility disadvantages the poorest and put them in greater risk of infection.

The harsh human and economic impact of the COVID-19 pandemic has highlighted social problems and made the Brazilian reality more visible, showing an insufficient health system, a lack of basic sanitation and housing infrastructure. Extreme material shortages are not only unacceptable, but they will introduce many difficulties in containing the pandemic.

\section{Funding}

This study was supported by CAPES, CNPq and FAPEMIG. This letter was based on observations and reflections about COVID-19 pandemic during studies supported by the funding agencies.

\section{Conflicts of Interest \\ None declared.}

\section{Ethical approval}

Not required.

\section{References}

1. Mata MS; Costa ICC. Composition of the Health Inequality Index analyzed from the inequalities in mortality and socioeconomic conditions in a Brazilian state capital. Ciênc Saúde Coletiva 2020; 25(5): 1629-1640. https://doi. org/10.1590/1413-81232020255.33312019

2. Massuda A. Primary health care financing changes in the Brazilian Health System: advance ou setback? Ciênc Saúde Coletiva 2020; 25(4): 1181-1188.

3. Barreto ML, Teixeira MG, Bastos FI, Ximenes RAA, Barata RB, Rodriguez LC. Successes and failures in the control of infectious diseases in Brazil: social and environmental context, policies, interventions, and research needs. Lancet 2011; 377(9780): 1877-1889. https://doi.org/10.1016/ S0140-6736(11)60202-X

4. GBD 2016 Brazil Collaborators. Burden of disease in Brazil, 1990-2016: a systematic subnational analysis for the Global Burden of Disease Study 2016. Lancet 2018; 392(10149): 760-775. https://doi.org/10.1016/S0140-6736(18)31221-2 